\title{
A PEDAGOGIA DO ESPORTE NA EDUCAÇÃO FÍSICA NO CONTEXTO DE UMA ESCOLA EFICAZ
}

\author{
DR. ANTONIO JORGE GONÇALVES SOARES \\ Professor Associado da Faculdade de Educação da Universidade Federal do Rio de Janeiro, \\ Doutorado na Universidade Gama Filho, Líder do Laboratório de Pesquisas em Educação \\ do Corpo (LABEC/NFRJ), Bolsista de Produtividade em Pesquisa do CNPq \\ (Rio de Janeiro - Rio de Janeiro - Brasil) \\ E-mail: antoniojsoares@pq.cnpq.br
}

MS. ALVARO REGO MILLEN NETO

Professor Substituto da Faculdade de Educação da Universidade Federal do Rio de Janeiro,

Doutorando na Universidade Gama Filho, Laboratório de Pesquisas em Educação do Corpo (LABEC/UFRJ), (Rio de Janeiro - Rio de Janeiro - Brasil)

E-mail: amillen@gmail.com

\section{MS. ALEXANDRE DA COSTA FERREIRA}

Professor da Secretaria Municipal de Educação do Rio de Janeiro, Mestrado na Universidade Gama Filho, (Rio de Janeiro - Rio de Janeiro - Brasil)

E-mail: xandreferreira@ig.com.br

\begin{abstract}
RESUMO
O artigo analisa o projeto de educação física desenvolvido em uma escola pública que pode ser considerada eficaz. A pesquisa foi desenvolvida através da imersão de um dos autores na referida escola. Para a coleta de dados foram utilizados diários de campo e fichas de observação etnográficas. As informações coletadas permitem inferir que: o desenvolvimento da educação física está associado a mecanismos institucionais que auxiliam a formação do clima escolar; por outro lado, a educação física também tem participação na configuração desse clima escolar; o papel de liderança se reflete na forma como a escola se estrutura; e a ideia de terminalidade construída a partir do engajamento da escola em competições esportivas pode contribuir para a construção de objetivos compartilhados.
\end{abstract}

PALAVRAS-CHAVE: Educação, Educação Física; escola eficaz; esporte; clima escolar. 
O artigo tem como escopo a compreensão do processo de construção social do currículo, com ênfase na educação física (EF) e nas outras práticas corporais, de uma escola de prestígio da rede pública de ensino do município do Rio de Janeiro. Partimos da hipótese de que o sucesso da educação corporal e/ou da EF curricular nessa instituição de ensino não está vinculado intrinsecamente ao modelo pedagógico adotado na disciplina ou nos demais momentos de educação corporal. $\bigcirc$ sucesso, segundo o ponto de vista da comunidade escolar e dos índices obtidos nas avaliações educacionais, talvez esteja associado a características próprias da escola investigada, tais como o clima escolar, a liderança e as metas e objetivos compartilhados (SAMMONS, 2008). O que tentaremos argumentar é que o sucesso da disciplina EF pode estar relacionado aos mecanismos institucionais que motivam professores e alunos a realizarem suas atividades no cotidiano escolar e incidem sobre a proficiência medida em avaliações institucionais.

A ideia de escola eficaz tenta relativizar o forte argumento dos determinantes familiares e sociais sobre o desempenho dos alunos.' Pois, apesar dos fatores de background familiar serem importantes para explicar o sucesso ou insucesso escolar, os estudos anglo-saxões indicam que a escola pode também exercer impacto no desempenho dos alunos para além dos determinismos da origem social. Isto é, existe uma influência da escola na aprendizagem, o chamado efeito escola (SAMMONS, 2008). Nesse sentido, as escolas eficazes apresentam características comuns que produzem mecanismos de eficácia escolar e, consequentemente, produzem sucesso escolar.

Para investirmos na análise desses mecanismos de eficácia escolar, consideraremos as duas linhas analíticas delineadas por Costa (2008), baseadas na tradição anglo-saxônica, para entender os motivos da efetividade escolar (school effectivess). A primeira se refere ao papel de possíveis lideranças, sobretudo de diretores, na construção de pontos de inflexão e curvas ascendentes na trajetória das escolas. $\bigcirc$ outro mecanismo retrata a dinâmica da cultura da escola e é conceituado como "clima escolar". Ainda observaremos os objetivos e visões compartilhados que, de acordo com Sammons (2008), são cruciais para qualquer tipo de organização coletiva de sucesso, incluindo as escolas. Nessa mesma direção, Lovisolo, Soares e Santos ( 1995 , p. 42-43) consideram que acordos e consensos sobre valores, meios e expectativas são fundamentais para o desenvolvimento de projetos educacionais, uma vez que

I. De acordo com Luz (2006), a publicação do Relatório Coleman, na década de 1960, teve forte impacto nas pesquisas educacionais e desencadeou um pessimismo acadêmico com relação ao papel exercido pela escola na aprendizagem. 
"se os atores não partilham de um horizonte comum de crenças ou representações é impossível a eficácia simbólica da escola, lugar onde, permanentemente, se ensina a operar com símbolos articulados ou não a um conjunto de valores" Obviamente, os valores em acordo não estão congelados, mas sujeitos a variações como qualquer elemento da sociedade e da natureza. Esperamos que nossa descrição forneça indícios para continuarmos a trabalhar na direção dessa hipótese.

Soares et al. (2008) nos fazem refletir sobre essa problemática em um estudo que buscou compreender como a escola dialoga com os fenômenos que envolvem possibilidades de fruição corporal e de aprendizagens de técnicas corporais nos tempos e espaços curriculares. Para isso, realizaram uma investigação, de cunho etnográfico, em uma escola da rede pública de ensino do município do Rio de Janeiro. Os autores observaram que os dois professores de EF dessa unidade escolar não apresentavam acordos sobre a perspectiva pedagógica de tratamento da EF no currículo. $\bigcirc$ desacordo gerava tensões quando o assunto em pauta era a formação de equipes esportivas representativas da escola. $\bigcirc$ professor, responsável pelas equipes, transformava o tempo e espaço de suas aulas em treinamento e seleção de jogadores, enquanto a professora indicava que suas aulas tinham por intenção permitir que os alunos e alunas praticassem esportes numa dimensão recreativa. A EF nessa escola era ineficaz, pois não tinha objetivos e visões compartilhados, o que refletiu num percentual alto de alunos que não participavam das aulas. Acrescente-se que a referida escola estava localizada num contexto favelizado, no qual a violência entre traficantes de drogas e a polícia interferia no cotidiano escolar. Além dos problemas de seu entorno, a gestão dessa escola estava longe de ser classificada como boa. No caso específico da EF, ficou constatado um percentual alto de alunos presentes no espaço das aulas da disciplina de EF que não participavam das mesmas (35,5\%), e quase I $5 \%$ eram ausentes. Outras dimensões do currículo observadas para a educação corporal foram os recreios e os tempos vagos. Esses espaços e tempos eram utilizados e esquadrinhados pelos alunos para prática de esportes, jogos e brincadeiras que reproduziam as relações de poder pautadas nas clivagens etárias e de gênero. $O$ significativo índice de não participação nas aulas de educação física era, de certa forma, consentido naquele contexto, na medida em que ambos os professores aceitavam o critério do gosto como justificava da participação ou da autoexclusão nas aulas, baseadas exclusivamente no esporte. Independentemente dos resultados sintetizados na pesquisa relatada anteriormente, devemos ter em mente que a transformação das aulas de EF em práticas esportivas optativas ou de participação voluntária no espaço e tempo curricular da escola não tem resolvido o problema da adesão às aulas de EF (COSTA, 2004). 
Nesse sentido, poderíamos pensar que todo o debate acerca do chamado movimento renovador, plural do ponto de vista ideológico e pedagógico, indicou para a necessidade de ampliação das experiências e conteúdos da EF escolar, a despeito das diferentes concepções pedagógicas. A partir desse pressuposto, Moura (2009) investigou duas escolas no município do Rio de Janeiro, uma da rede privada de ensino, que afirmava trabalhar a EF escolar na perspectiva da pedagogia crítica, e outra da rede pública, onde essa disciplina era trabalhada na perspectiva da pedagogia esportiva. Em ambas as escolas o pesquisador observou turmas do segundo segmento do ensino fundamental. Notem que o esporte também era o conteúdo dominante nas escolas investigadas e Moura (2009) ainda observou que os alunos que, em tese, vivenciavam a pedagogia crítica nas aulas, não representavam a EF de modo diferente dos alunos que estudavam na escola pública. No entanto, essas escolas podem ser consideradas como bem organizadas do ponto de vista da gestão. As aulas de EF, independentemente das concepções e experiências pedagógicas, possuem identidade com as respectivas escolas e com suas respectivas propostas de EF. Destaque-se que a adesão dos alunos à EF na escola municipal situou-se acima dos $90 \%$, e essas aulas, mesmo baseadas no modelo esportivizante, estão longe de serem excludentes, ainda que em determinados momentos os mais habilidosos sejam selecionados para as equipes esportivas.

\section{METODOLOGIA}

Este estudo foi realizado em uma escola da Secretaria Municipal de Educação do Rio de Janeiro (SME/RJ). Trata-se de uma unidade escolar da $7^{a}$ Coordenadoria Regional de Ensino - que tem mais I 26 escolas sob sua responsabilidade - localizada no bairro do Tanque, em Jacarepaguá. No período da coleta de dados, a instituição tinha | | 8 | alunos regularmente matriculados, divididos em 26 turmas que iam do sexto ao nono ano do Ensino Fundamental. $\bigcirc$ corpo docente da instituição era composto por 56 professores, sendo cinco de EF. A unidade possuía um corpo técnico-administrativo composto de uma diretora-geral, uma diretora-adjunta, uma coordenadora pedagógica e uma orientadora educacional. Já a equipe de apoio era constituída por dezesseis funcionários, dentre eles: merendeiras, serventes, inspetores e agentes administrativos.

Se a escolha do cenário de investigação se deu em virtude do reconhecimento social da escola investigada - constituído, em parte, pelas muitas conquistas obtidas nas competições estudantis ${ }^{2}$-, podemos adiantar que o prestígio dessa instituição

2. Sobre a construção social da excelência dessa escola, a partir de sua participação em competições esportivas, ver Millen Neto, Soares e Ferreira (201 I). 
não está apenas fundamentado na imagem de sucesso com o esporte escolar. Essa escola possui fama entre professores, alunos e seus responsáveis. Se considerarmos que uma escola de qualidade tem a obrigação de evitar repetência, evasão e garantir um desempenho satisfatório dos seus alunos, os números da escola confirmam esses pressupostos de qualidade. Os índices de aprovação na unidade, desde 1995, estão acima de $90 \%$. Informamos que na época da coleta de dados os números referentes ao ano letivo de 2008 ainda não estavam disponíveis. Destaquemos que nos anos letivos de 2007 e 2008, as escolas da rede pública do município do Rio de Janeiro funcionavam sob o regime de Ciclo de Formação, não havendo reprovação nos períodos iniciais e intermediários.

No caso da instituição estudada, as taxas de aprovação internas foram legitimadas pelos resultados obtidos no Índice de Desenvolvimento da Escola Básica (IDEB). Em 2007, a escola obteve o IDEB de 5, I, enquanto a média das escolas da cidade do Rio de Janeiro para os anos finais do ensino fundamental foi de 4,3 e a média brasileira das escolas municipais nesse mesmo segmento foi de 3,4. Esse resultado colocou a escola em $3^{\circ}$ lugar entre as unidades escolares da $7^{\mathrm{a}} \mathrm{CRE}$, na $16^{a}$ posição no ranking das escolas públicas da rede municipal e na $30^{a}$ colocação entre todas as unidades públicas do Estado do Rio de Janeiro. ${ }^{3}$

Nos meses seguintes à divulgação dos resultados do IDEB 2007, revistas especializadas em educação realizaram diversas análises e tornaram públicas as coincidências encontradas entre as escolas que obtiveram os melhores resultados no exame. Não eram somente o suposto empenho docente e o apoio da comunidade que indicavam o sucesso das escolas. Constatou-se também que nessas escolas a média de permanência do diretor no cargo era de no mínimo três anos, contra a média nacional de apenas um ano. Sem dúvida, a gestão dessas escolas se relaciona com a dedicação docente. Nesse sentido, devemos ver que a escola estudada possui um quadro gestor com longo tempo de permanência. Observemos que a atual diretora geral da escola, professora Vera, ocupa o cargo desde 1992, sendo que antes disso havia sido diretora adjunta durante 12 anos. Com isso, podemos afirmar que a permanência de gestores de longo prazo, com amplo apoio docente e num regime de eleição direta de diretores, indica a continuidade de projetos pedagógicos e a possibilidade de construção de uma identidade escolar continuamente elaborada a partir de uma estabilidade institucional.

3. De 2007 para 2009 o IDEB da escola estudada teve uma pequena queda (de 5, I para 5,0). No mesmo período, o decréscimo do índice geral obtido pelas escolas municipais do Rio de Janeiro foi muito mais significativo. Para os anos finais do ensino fundamental a avaliação foi de 4,3 para 3,6, colocando a escola na $9^{a}$ posição entre as escolas da rede municipal de ensino do Rio de Janeiro. 
Ainda com relação ao modo de gestão da escola estudada, outros de seus atributos se aproximam, com maior ou menor intensidade, com o que parte da literatura preconiza para uma boa administração escolar. Nesse sentido, Paro (20 l 0) ressalta como característica de uma direção escolar democrática a postura de um agente político, para além de uma simples gerência educacional. Tal postura exigiria do gestor escolar "uma mediação administrativa sui generis, tanto em termos de racionalização do trabalho quanto de coordenação do esforço humano coletivo" (PARO, 20 I0, p. 776). Reynolds e Teddlie (2008), com base em pesquisas empíricas desenvolvidas no Reino Unido, acrescentam a essa assertiva as seguintes características de gestores de escolas que fazem a diferença: liderança estável e adequada, estrutura organizacional adequada e informal, liderança compartilhada com outros membros, resistência a mudanças externas, relacionamento íntimo entre os administradores e bom uso do pessoal de apoio acadêmico.

Outra característica que indica excelência, encontrada na escola escolhida para fazer parte da investigação, se refere à multiplicidade de possibilidades educacionais ofertadas aos alunos. Além das atividades que fazem parte do currículo ordinário, prescrito pela Secretaria de Educação e vivido no cotidiano escolar, a escola disponibiliza para seus alunos, em forma de oficinas, as seguintes atividades: informática, esportes, dança, músicas e italiano.

Para compreender o processo de construção social do currículo da EF na instituição estudada foi realizada uma investigação de natureza qualitativa. Os dados foram coletados por meio de entrevistas com os professores de EF e observações participantes do cotidiano escolar - principalmente das aulas de EF, oficinas de esportes e de dança e da participação dos alunos nos Jogos Estudantis. O período da pesquisa de campo foi de 20 de agosto a 19 de dezembro de 2008. Durante esse período observamos 12 dias de oficinas de esportes, 15 treinamentos das equipes esportivas e 25 recreios, e acompanhamos as equipes esportivas em eventos realizados fora da escola.

Para realizarmos a coleta dos dados, o projeto de pesquisa foi apresentado e aprovado pelo Comitê de Ética em Pesquisa Envolvendo Seres Humanos da Universidade Gama Filho. O projeto também foi submetido à avaliação do Departamento Geral de Educação (E/DGED) e obteve parecer favorável. A participação de todos os indivíduos envolvidos na pesquisa foi voluntária.

\section{AS AULAS DE EDUCAÇÃO FÍSICA}

As aulas da disciplina de EF na escola investigada são obrigatórias e têm uma carga horária semanal de dois tempos de 50 minutos. $\bigcirc$ planejamento anual é 
dividido em três períodos, que contemplam simultaneamente, em todos os anos de escolarização observados, os quatro esportes de quadra que têm mais tradição na EF escolar brasileira: handebol, basquetebol, voleibol e futsal. A despeito dos conteúdos abordados, não foi verificada qualquer separação por sexo nas turmas observadas - foram acompanhadas as aulas de EF das turmas I 603 (6 $6^{\circ}$ ano), I703 ( $7^{\circ}$ ano), I 805 ( $8^{\circ}$ ano) e 1901 ( $9^{\circ}$ ano). Segundo a orientadora pedagógica da escola investigada, o planejamento anual de EF é elaborado pela equipe de professores da disciplina e caminha em consonância com a proposta do Projeto Político Pedagógico (PPP) da escola. No entanto, a reunião de planejamento da equipe de EF acontece sem a presença dos demais professores. Essa disjunção entre os professores de EF e os outros docentes durante o planejamento acontece por opção da própria equipe. Vale registrar que na reunião de planejamento da escola os docentes agrupam-se pelas séries em que lecionam e não por disciplina. Se, por um lado, a construção do planejamento da EF em paralelo às demais indica um afastamento do núcleo dos objetivos compartilhados nessa escola, sua presença e articulação no PPP denotam que se trata de uma articulação diferenciada, mas não ausente. A EF compartilha, a seu modo, dos objetivos comuns da instituição investigada. Inclusive, há que se destacar que as manifestações esportivas se constituíram em uma das temáticas norteadoras da atualização do PPP em 2008.

Devemos realçar que, apesar dessa escola trabalhar com o modelo tradicional ou esportivizante de EF, essa disciplina ocupa um lugar de destaque no cotidiano escolar. Mesmo que reconheçamos os avanços do debate pedagógico e metodológico na EF brasileira a partir dos anos de 1980 e de 1990, no percurso deste estudo não questionaremos o modelo adotado pela escola estudada. Nossa questão é: o que faz essa prática tradicional ser eficaz nesse ambiente escolar quando o debate contemporâneo da EF brasileira indica que esse modelo é improdutivo e excludente? Desejamos apresentar uma leitura de como as práticas corporais tratadas e vivenciadas em uma escola considerada eficaz se articulam com os possíveis fatores que promovem a eficácia escolar.

As aulas de EF acontecem geralmente na quadra. No entanto, no ano letivo de 2008 houve coincidência de dias e horários entre algumas turmas, e por este motivo algumas aulas foram ministradas em outros espaços, ou seja, no pátio da escola e em uma área pública de lazer conhecida como "pista" - área que dispõe de duas quadras esportivas e uma pista de skate localizada nas cercanias da escola. Essa situação causou mal-estar entre os docentes, que questionaram a direção sobre o arranjo de horários, uma vez que seria possível a disposição das aulas em horários diferenciados. A fim de resolver essa questão, os docentes de EF lançaram mão de duas estratégias: realizar as aulas de forma conjunta no espaço da quadra ou 
optar pelo revezamento na utilização do espaço - enquanto um professor utilizava a quadra, o outro trabalhava no pátio ou nas cercanias da escola. Isso demonstra como a equipe dos professores de EF dessa escola se articula para resolver seus problemas no cotidiano.

O material utilizado nas aulas de EF é composto de bolas oficiais, redes, cones, cordas, aros e coletes e é abundante, bem conservado e de boa qualidade. $\bigcirc$ material das aulas é disponibilizado para todos, sendo utilizado também nas oficinas de esporte e no treinamento das equipes da escola. De acordo com o relato de um professor mais antigo dessa unidade, nem sempre a escola contou com essa quantidade de material. $O$ investimento no material para a EF se deu na medida em que essa disciplina teve seus objetivos e conteúdos incluídos no PPP da escola. As disputas nos espaços curriculares geram efeitos na qualidade da formação, mas tais disputas só podem se dar num espaço em que os docentes possuem identidade com a escola e com o trabalho que realizam. Temos que ter em mente esse argumento para pensarmos que a qualidade da EF e de outras disciplinas está também vinculada a outras qualidades da escola que, segundo os dados subjetivos e objetivos, é considerada eficaz na Rede de Ensino Municipal do Rio de Janeiro.

\section{A PARTICIPAÇÃO DOS ALUNOS}

Os dados sobre a participação dos alunos foram coletados com observações in loco e categorizados da seguinte forma: alunos presentes $(97,45 \%)$ e alunos ausentes (2,45\%). Dentre os presentes, apenas 2,55\% puderam ser considerados alunos presentes não participantes. Essa realidade é bem diferente daquela retratada no estudo anteriormente citado (SOARES et al., 2008), realizado em uma instituição pública de ensino do mesmo município. Naquele contexto verificou-se um significativo percentual de alunos ausentes ( $15,5 \%$ ), devido à violência urbana que atingia a localidade na qual estava inserida a escola. No caso da escola investigada, outros fatores, além da ausência da violência nas cercanias da unidade, contribuíram para o baixo número de alunos ausentes. $\bigcirc$ comprometimento e a identificação dos alunos com a unidade escolar, associados à valorização do espaço da escola pelos pais, como locus privilegiado de socialização e aprendizado, também parecem corroborar a formação de um ambiente positivo na escola. Em outras palavras, a maior adesão dos alunos denota que há um clima escolar favorável gerado na EF e em outros espaços e tempos curriculares.

\section{OFICINAS DE ESPORTE}

As oficinas de esporte surgem quando a escola inicia sua participação nos Jogos Estudantis, organizados pela Secretaria Municipal de Educação do Rio de Janeiro 
em 1993. No ano de 2008, essas oficinas foram desenvolvidas aos sábados, das 9 h30 às 15h. Observou-se que os alunos começavam a chegar para as oficinas às 9h. Mesmo sendo avisados durante a semana do horário da realização das oficinas esportivas nas quais estavam envolvidos, muitos alunos chegavam à escola antes do início das mesmas. E também não foram raras as vezes em que, mesmo após o encerramento das oficinas, os alunos permaneceram na escola, conversando, brincando, estudando ou esperando algum amigo que ainda realizava alguma atividade esportiva. Esse é mais um indício de acolhimento que essa unidade escolar proporciona aos alunos.

Durante as oficinas era evidente a preocupação dos professores em relação à correção dos gestos e técnicas esportivas durante a execução dos fundamentos de cada modalidade esportiva. Após o aquecimento e treinamento das técnicas ocorria o jogo. Com esta finalidade, os alunos eram divididos em equipes, das quais pelo menos uma era constituída somente por alunos das equipes esportivas que representavam a escola. As demais equipes eram formadas pelo restante do grupo participante. Nesse momento, as atenções dos professores, como era esperado, estavam voltadas para o desempenho das equipes representativas da escola. No entanto, podemos considerar esse espaço e tempo como exclusão dos menos habilidosos ou como uma oportunidade da escola também oferecer espaços para o desenvolvimento da excelência, além dos espaços e tempos obrigatórios na grade curricular.

Os ex-alunos, mesmo não podendo mais participar das competições escolares, compareciam e participavam das oficinas de esporte. Alunos não envolvidos nas oficinas também frequentavam sistematicamente a escola aos sábados. Geralmente se apropriavam dos espaços ao redor da quadra para estudar, conversar, ouvir música, ensaiar para apresentações da escola ou observar os treinamentos das oficinas de esporte. Esse clima de sociabilidade entre participantes e não participantes das oficinas indica que essa atividade provoca movimento e sinergia na escola, ao contrário de exclusão, como normalmente se pensa no campo da EF. Além de propiciar um momento de fruição corporal, lazer e socialização para alunos e alunas, as oficinas de esporte também têm por fim treiná-los, em busca de um melhor desempenho nas competições esportivas das quais a escola participa.

\section{OFICINA DE DANÇA}

Assim como as oficinas esportivas, a introdução da oficina de dança no currículo da escola investigada remonta a meados da década de 1990. De acordo com a professora Beatriz, mesmo antes da criação da oficina de dança já existia na escola um movimento, incentivado pela direção, para a inclusão de horários de ensaio no cotidiano escolar. O objetivo desses ensaios era organizar coreografias que 
pudessem ser apresentadas em dias festivos e datas comemorativas celebrados na escola. Observe que esse é um procedimento tradicional no campo da EF escolar. Porém, a forma como esses ensaios foram introduzidos no cotidiano escolar gerou resistência por parte das professoras Beatriz e Cristina. Não havia na carga horária das professoras, e tampouco no orçamento da escola, tempos de aula destinados para a realização dos ensaios. Geralmente, esses ensaios aconteciam no período entre o turno da manhã e o turno da tarde ou em tempos vagos das professoras. Aqui temos mais um exemplo do vínculo dos docentes com a instituição.

A partir de 1999, a oficina de dança passou a funcionar de maneira regular no cotidiano dessa escola. Segundo Beatriz, graças à efetivação do PPP da escola junto à CRE, a oficina de dança tomou contornos mais "profissionais". Observemos as palavras da professora Beatriz: "com a aprovação do projeto, foram introduzidos na minha carga horária tempos de aula para me dedicar à oficina de dança. Dessa forma, ficou mais profissional". Apesar do esforço da direção da escola em acelerar o processo, a data da liberação pela SME das horas extras de trabalho para as professoras envolvidas nas oficinas continua incerta, fato que ainda causa desconsforto para essas docentes a cada ano. Em 2008, a oficina de dança foi oferecida às terças e sextas-feiras no contraturno e, em média, o número participantes foi de 20 alunos por turma.

Verificamos que existia um controle sistemático da frequência dos alunos nessa oficina, por meio de chamada. O PPP da escola esclarece: "Será cobrada assiduidade para garantir um rendimento satisfatório. Mais de duas faltas não justificadas no mês eliminarão o aluno [das oficinas]". Nesse contexto, durante o período da pesquisa de campo não constatamos nenhuma ausência nas turmas que acompanhamos, nem impontualidade dos alunos integrantes dessas oficinas. Observe-se que essa normatização demonstra o comprometimento dos integrantes com o grupo e com a professora e o cumprimento da norma estabelecida pela escola.

De acordo com a professora Beatriz, dois momentos durante o ano são tratados de maneira especial pela oficina de dança. $\bigcirc$ primeiro é a apresentação realizada ao término de todo ano letivo no auditório da escola. $O$ segundo momento é a Mostra de Dança das escolas da rede pública do município do Rio de Janeiro. $\bigcirc$ sucesso dessas atividades artísticas está, de certo modo, vinculado à estruturação de metas para a realização do evento final da escola e participação na mostra de dança. Metas que motivam alunos e professores a se envolverem com essa atividade, para além do currículo ordinário. Todavia, tal envolvimento só é possível face à gestão organizada, a identidade dos professores com a escola e aos processos de lutas nas diferentes instâncias, no sentido de garantir outras experiências curriculares e condições de trabalho. 
Os treinamentos das equipes esportivas da escola ocorriam também de segunda a sexta-feira durante o "horário de almoço", ou seja, das I 2h às I3h. Os dias de treinamento variavam de equipe para equipe. Cabe ressaltar que, conforme a proximidade das competições, os treinamentos podiam ser intensificados. Esses treinamentos são encerrados quando termina a participação da escola nos Jogos Estudantis - as equipes de futsal masculino, por não terem progredido na competição, tiveram suas atividades encerradas no mês de agosto. Os treinamentos realizados durante a semana tinham o mesmo formato das oficinas de esporte e das aulas de EF. A diferença, nesse caso, ficava por conta do tempo de duração. Enquanto um treinamento realizado entre os turnos letivos tinha duração aproximada de 40 minutos, as atividades físicas e esportivas nas oficinas podiam durar até 120 minutos.

De maneira diferente da ocorrida nas oficinas de esporte e de dança, o tempo despendido pelos professores nesses treinamentos, assim como para acompanhar as equipes esportivas em dias de competição, não era fixado em suas cargas de trabalho, e eles tampouco recebiam remuneração por esse trabalho extra. Condição semelhante a essa é retratada por Moura (2009), em que os professores também não recebiam nenhuma remuneração ou folga em troca dos dias de trabalho à frente das equipes esportivas da escola analisada.

\section{A PARTICIPAÇÃO DA ESCOLA NOS JOGOS ESTUDANTIS}

Ao longo de sua história, a escola investigada participou de diversas competições esportivas entre escolas. Contudo, nenhuma delas é considerada tão emblemática pela instituição como os Jogos Estudantis da Cidade do Rio de Janeiro. Trata-se de uma competição esportiva restrita a alunos matriculados regularmente na rede municipal de ensino do Rio de Janeiro. Até 2008, foram realizadas 17 edições, sendo a EM Silveira Sampaio, estudada por Moura (2009), seguida pela instituição que estudamos, as escolas com o maior número de vitórias.

Em 2008, a escola estudada disputou as seguintes modalidades: futsal masculino, categorias infantil e infanto-juvenil; voleibol masculino, categorias infantil e infanto-juvenil; voleibol feminino, categoria infantil; handebol masculino, categoria infantil; handebol feminino, categoria infantil; basquetebol masculino, categoria infantil; e basquetebol feminino, categoria infantil. Além dessas modalidades de quadra, a escola participou do xadrez e do tênis de mesa, ficando de fora somente do atletismo. Sobre a não participação da escola nas competições de atletismo, a professora Tereza afirmou: "não adianta nós levarmos nossa equipe, é perda de tempo. Lá na Silveira eles têm condições excepcionais, contam com uma pista e até com patrocínio". Essas condições, segundo a professora, justificam o bom 
desempenho da EM Silveira Sampaio na modalidade atletismo, dados também mencionados por Moura (2009). Segundo o autor, existe um projeto de atletismo gerido por um ex-professor da escola que colabora no treinamento e conta com patrocínio externo. Observemos que a escola tem no esporte e nas competições esportivas, no sentido mais corriqueiro e tradicional da EF, o centro de sua identidade curricular. Tal identidade, aliada a uma gestão escolar organizada e estável no cotidiano, constrói no currículo dessa escola possibilidades de educação do corpo, pela EF e pelas oficinas de esporte e de dança, que lidam com diferentes gostos e desejos de desenvolvimento dos alunos no campo expressivo, mesmo numa perspectiva tradicional da EF.

\section{CONSIDERAÇÕES FINAIS}

A partir da perspectiva adotada no texto, sob o olhar dos estudos sobre eficácia escolar, tentamos iluminar outros aspectos da dinâmica da EF inserida no contexto escolar que ainda são pouco explorados pela tradição acadêmica dessa área de intervenção pedagógica. Apontamos para o imperativo de compreendermos que essa disciplina, independentemente do modelo pedagógico adotado, pode funcionar em determinados contextos em consonância com fatores que ultrapassam suas especificidades e transcendem aos aspectos da crítica normativa das pedagogias críticas à pedagogia esportiva. O clima ou ambiente escolar é um desses aspectos que, de certo modo, regulam a forma de participação, ou o engajamento, de professores e alunos envolvidos com a EF e com outros projetos de educação corporal na escola. No caso específico do cenário investigado, a positividade do ambiente vivenciado tem influenciado sobremaneira a dinâmica das aulas de EF e constitui um atrativo e/ou facilitador para a adesão dos alunos - como vimos, a taxa de adesão é alta. $\bigcirc$ papel de liderança exercido por uma diretora que está no cargo há mais de uma década também tem que ser levado em consideração. É muito provável que a forma como a escola está estruturada seja, em parte, reflexo dessa liderança construída coletivamente.

Nesse sentido, sem desconsiderar a relevância e necessidade de se debater fundamentos e métodos de ensino específicos para a EF escolar, consideramos a necessidade de pensarmos esse componente curricular de modo integrado às problemáticas da escola como um todo. Essa integração é precípua para a reflexão das possibilidades da EF na escola e também para a própria qualidade do ensino. Como o relatório de Sammons (2008) nos aponta, objetivos e visões compartiIhados são uma das características que sobressaem nas escolas identificadas como eficazes. E, por outra via, o bom ou mau funcionamento de uma disciplina pode constituir chaves para se pensar a qualidade do ensino e os possíveis entraves que a educação básica precisa enfrentar. 
A possibilidade de um componente curricular contribuir para ativar um ou mais parâmetros de eficácia escolar é outro aspecto a ser explorado na dinâmica entre a escola, seus componentes curriculares e a eficácia escolar. No caso investigado neste estudo, os dados apontam que a EF e os demais tempos e espaços de práticas corporais têm participação na configuração do clima escolar. Do mesmo modo, podemos considerar que a ideia de terminalidade construída a partir do engajamento dessa escola em competições esportivas contribuiu para a construção de objetivos e visões compartilhados. Todavia, há que se destacar que talvez o sucesso dessa disciplina e das diferentes oficinas oferecidas no ambiente escolar pode estar vinculado ao fato do currículo possibilitar experiências para todos e, ao mesmo tempo, oferecer diferenciadas experiências que caminham na direção do gosto e/ou da aptidão.

\section{The Pedagogy of Sport in Physical Education in the Context of a Successful School}

ABSTRACT: The article analyses the project of Physical Education developed in a successful public school. The research was developed using the observant participation method. For the data collection we used field notes and ethnographic observation. The collected information allow us to infer that: the development of physical education is associated with institutional mechanisms that help the formation of school climate; on the other hand, physical education also plays a role in shaping this school climate; the role of leadership is reflected in how the school is structured; and the idea of terminality constructed by the engagement of the school in sport competition can contribute in the construction of shared goals.

KEYWORDS: Education; Physical Education; successful school; sport; school climate.

\section{La pedagogía del deporte en la Educación Física en el contexto de una escuela exitosa}

RESUMEN: El artículo analiza el proyecto de educación física en una escuela pública que puede ser considerada exitosa. La observación participante fue el método elegido para la investigación. Para la recolección de datos fueron utilizados diarios de campo y observación etnográfica. Las informaciones recolectadas permiten inferir que: el desarrollo de la educación física está asociado a mecanismos institucionales que auxilian la formación del clima escolar; por otro lado, la educación física también tiene participación en la configuración de ese clima escolar; el papel de liderazgo se refleja en la forma como la escuela se estructura; y la idea de terminalidad construida a partir del compromiso de la escuela en competiciones deportivas puede contribuir para la construcción de objetivos compartidos.

PALABRAS-CLAVE: Educación; Educación Física; escuela exitosa; deporte; clima escolar. 


\section{REFERÊNCIAS}

COSTA, R. C. A educação física no CETEP Marechal Hermes: um estudo do cotidiano escolar. 2004. Dissertação (Mestrado em Educação Física) - Universidade Gama Filho, Rio de Janeiro, 2004.

COSTA, M. Prestígio e hierarquia escolar: estudo de caso sobre diferenças entre escolas em uma rede municipal. Revista Brasileira de Educação, Rio de Janeito, v. I3, n. 39, set./dez. 2008.

LOVISOLO, H.; SOARES, A. J. G.; SANTOS, M. D. Educação e educação física em escolas do Rio de Janeiro. In: LOVISOLO, H. Educação fisica: arte da mediação. Rio de Janeiro: Sprint, 1995.

LUZ, L. S. Os determinantes do desempenho escolar: a estratificação educacional e o efeito valor adicionado. In: ENCONTRO NACIONAL DE ESTUDOS POPULACIONAIS, I5., Caxambú, 2006. Anais ... Caxambú: Associação Brasileira de Estudos Populacionais, 2006.

MILLEN NETO, A. R.; SOARES, A. J. G.; FERREIRA, A. C. Políticas de esporte escolar e a construção social do currículo de educação física. Motriz, Rio Claro, v. 17, n. 3, p. 4l 6-423, jul./set. 201 I.

MOURA, D. L. Cultura e educação física: uma análise etnográfica de duas propostas pedagógicas. 2009. Dissertação (Mestrado em Educação Física) - Universidade Gama Filho, Rio de Janeiro, 2009.

PARO, V. H. A educação, a política e a administração: reflexões sobre a prática do diretor da escola. Educação e Pesquisa, São Paulo, v. 36, n. 3, p. 763-778, set./dez. 2010.

REYNOLDS, D.; TEDDLIE, C. Os processos da eficácia escolar. In: BROOKE, N.; SOARES, J. F. (Org.). Pesquisa em eficácia escolar: origens e trajetórias. Belo Horizonte: Ed. da UFMG, 2008.

SAMMONS, P. As características-chave das escolas eficazes. In: BROOKE, N.; SOARES, J. F. (Org.). Pesquisa em eficácia escolar: origens e trajetórias. Belo Horizonte: Ed. da UFMG, 2008.

SILVA, T. T. Documentos de identidade. 4. ed. São Paulo: Autêntica, 2002.

SOARES, A. J. et al. Tempo e espaço para educação corporal no cotidiano de uma escola pública. In: ENCONTRO NACIONAL DE DIDÁTICA E PRÁTICA DE ENSINO, I4., Porto Alegre, 2008. Anais... Porto Alegre: ENDIPE, 2008.

Recebido em: 22 ago. 2010

Aprovado em: 20 mar. 2011

Endereço para correspondência: Antonio Jorge Gonçalves Soares

Av. Pasteur fundos $2^{\circ}$ andar Campus Praia Vermelha Rio de Janeiro-RJ CEP: $22290-240$ 